\title{
The Negative Impact of Social Media on Environmental Preservation, Activities of Tourism Marketing
}

\author{
Ian Simon \\ Doctor in Public Administration, \\ Program Head, College of Hospitality Management \\ Email: iansimonr@gmail.com
}

\begin{abstract}
The use of social media to promote tourism is evidently showing a significant and important role in the industry. Most research studies focus in the areas of social media marketing and its impact on tourism industry, without giving more emphases its negative effect on environmental preservation. The aim of this study is to assess the underlying issues associated with tourism marketing and environmental preservation which are often overlooked. The purpose is to explore deeply the impact of social media marketing as platform use to promote tourism and its negative effect on environmental preservation.
\end{abstract}

\section{Project Description}

Humans can only do business using natural resources; neither can attain sustainable growth without conservation. Even the smallest gadget sold online, somewhat has its small part come from the earth's natural resources, thus this study explore the correlation between doing business and environmental preservation in which naturally can't be detached. As we all know that these two commodities are inseparable in so many ways. In essence, business means nothing without natural resources.

Preservation, in contrast to conservation, attempts to maintain in their present condition areas of the Earth that are so far untouched by humans. This is due to the concern that mankind is intruding onto the environment at such a rate that many untamed landscapes are being given over to human development in particular to tourism sector, and that we our losing too much of what is 'natural' (Buchdahl, Hare, aric.,2000). 
Tourists all over the world constantly look for untouched lands and real nature, a scientific study, which explored through decades of archaeological data and found that there are no remaining pristine places on Earth that are unaffected by human society and activity, and there probably hasn't been one for thousands of years. Human impact on this planet is evident; we modified ecosystems and landscapes (Boivin, N. L. et al.2016).

\section{Research topic}

In this paper, we examine the effect of social media marketing to promote tourism and its effect to the preservation of the environment and analyze the heterogeneity of tourism consumer by investigating tourism consumers, Tourism has its always indivisible relationship with the environment and this study may help promote spread awareness to maintain the preservation of our natural environment for the benefits of the future generation. Doing business without causing damage of natural resources is one of the world's number one issues to combat sustainable growth. This study may also open new ideas to eco-friendly business companies on how to make use of the social media as platform to promote tourism without compromising environmental preservation.

Social media embeds news and information about social issues in a social context, which provides a personal context for individuals. Information is filtered through friends (Metzger et al., 2010), and sites such as Facebook provide information based at least partially on an individual's previous information habits (Pariser, 2011). In addition, social media use is often conducted in visual form, with half of social media users sharing or reposting news stories, images, or videos (M. Anderson \& Caumont, 2014), and climate change is effectively communicated visually (van der Linden, Leiserowitz, Feinberg, \& Maibach, 2014). In short, social media personalizes social issues in several ways, and is thus an appropriate lens through which to analyze climate change opinion.

Social Media Marketing is having a tremendous impact on tourism as business growth and performance are taking place at an astronomical rate: The profit margins and the expenditure on marketing and advertizing campaigns have reduced substantially, this has made it possible for some of the hotels to pass on the benefit to the customer and increase their business share in an industry that is highly competitive because of the power of the social media and the internet possibilities. (Rashmi Gururaja, 2015). 


\section{Methodology}

The study will use mixed methods research design to validate findings using quantitative and qualitative data sources. It is a convergent design to compare findings from qualitative and quantitative data sources. It involves collecting both types of data at roughly the same time; assessing information using parallel constructs for both types of data; separately analyzing both types of data; and comparing results through procedures such as a side-by-side comparison in a discussion, transforming the qualitative data set into quantitative scores, or jointly displaying both forms of data. Mixed methods can be an ideal technique to assess complex interventions such as PCMHs (Homer, Klatka, Romm, et al., 2008; Nutting, Miller, Crabtree, et al., 2009).

The research method also helps offering a better comprehension of the nature of tourism policy issues. Having established the overarching motivation for conducting research concerning this topic, it is necessary to reflect upon how this can be appropriately achieved. A qualitative mixed methods framework will be adopted, enabling a reflexive and inductive study design. In-depth interviews will be conducted, including analysis of aggregated images yielded from search result across social platform and collection of statistical data from environmental monitoring agencies from different countries. Also This will seek to produce rich understandings of respondents' perceptions on environmental issue and how this links to social media and tourism marketing. This will enable the relevant data to be gathered in order to answer the study's research questions. The collected results are analyzed in a subjective and interpretative way and can usually be generalized within restricted limitations.

\section{Concept and Theory}

The main focus of the study involves the theory on defining and analyzing the impact of social media on environmental conservation, activity of tourism marketing. Primary attention is given to the negative effect to the environmental preservation with the concepts of sustainable development. The concept of sustainability is quite wide. It will be explained briefly in this paper also touching upon sustainability in tourism industry and stressing especially sustainable nature tourism. Evidently, tourism marketing strategy focuses more on social networking platform. Social media plays a significant role in many aspects of tourism, especially in information search and decision-making behaviours, tourism promotion 
and in focusing on best practices for interacting with consumers. Leveraging off social media to market tourism products has proven to be an excellent strategy (Kowk et al. 2017).

Like conservationists, some preservationists support the protection of nature for purely human-centred reasons. Stronger advocates of preservation however, adopt a less human-centred approach to environmental protection, placing a value on nature that does not relate to the needs and interests of human beings. Deep green ecology argues that ecosystems and individual species should be preserved whatever the cost, regardless of their usefulness to humans, and even if their continued existence would prove harmful to us. This follows from the belief that every living thing has a right to exist and should be preserved.

Human impact on the environment or anthropogenic impact on the environment includes changes tobiophysical environments and ecosystems, biodiversity, and natural resources caused directly or indirectly by humans, including global warming, environmental degradation Encyclopedia of Sustainable Development (2014).

\section{Expected Outcomes}

In terms of scientific contribution, the expected results of the project are related to advancement of theoretical understanding of social media marketing on tourism related to natural preservation. The proposed study will contribute to the national and international knowledge base on environmental preservation. The study provides a unique opportunity to increase knowledge, awareness and the understanding of natural preservation. It also helps spread awareness to tourism sector using social media to promote preserved natural wild life. It will shed light on the possibilities of social media marketing use to promote tourism business and the responsibilities of social media users in preserving the environment. It also provides a real opportunity to inform the tourism sector and practice to address specific change to support local government on environmental conservation.

All studies will be developed and carried out in collaboration with different social media platforms, like Facebook, Instagram, Youtube etc., with relevant local and international agencies on natural wildlife preservation from different countries, written up for publication, disseminated through dialogue and policy briefs. 
Tentative Time Plan

\begin{tabular}{|c|c|c|}
\hline YEAR & MONTHS & TASK \\
\hline & $1-6$ & $\begin{array}{l}\text { Literature review Negotiate access to meetings., formulate survey questions. } \\
\text { Contact and establish reliable form of correspondence to be used. }\end{array}$ \\
\hline 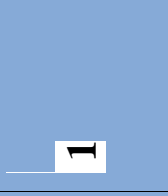 & $7-12$ & $\begin{array}{l}\text { Literature review Prepare for interviews; contact potential interviewees } \\
\text { Observation of meetings. begin personal journal of expectations to be } \\
\text { continued throughout time abroa and incorporated into research presentation } \\
\text { upon return }\end{array}$ \\
\hline \multirow[b]{2}{*}{$N$} & $13-18$ & $\begin{array}{l}\text { Conduct interviews Transcribe interviews Observation of meetings. Collect } \\
\text { statistical data from nature reserved/ protected environment from different } \\
\text { countries. Conduct evaluation and input physical observation on specific location. } \\
\text { Complete any unread literary and academic works from the 'sources' list } \\
\text { and incorporate any appropriate information into research. }\end{array}$ \\
\hline & 19-24 & $\begin{array}{l}\text { Analyze data from interviews and and personal experience and observations } \\
\text { Update literature review }\end{array}$ \\
\hline \multirow[b]{2}{*}{$m$} & $25-30$ & $\begin{array}{l}\text { Revisit literature review Data analysis Write up. Collect and organize results. } \\
\text { Maintain communication with environmental monitoring agencies, relaying } \\
\text { data.. }\end{array}$ \\
\hline & $31-36$ & $\begin{array}{l}\text { Administer Survey to focus group. Collect and organize results. Organize all } \\
\text { data in comprehensive manner to show variance of experiences in relation } \\
\text { Write up }\end{array}$ \\
\hline
\end{tabular}




\section{References}

1. Int. J. Environ, Spring (2016) Effects of Social Media on the Environmental Protection Behaviour of the Public. ISSN: 1735-6865, . Res., 10(2):237-244

2. Shahgerdi A. Environmental impacts of educational tourism on the city of Famagusta, Northern Cyprus (Doctoral dissertation, Eastern Mediterranean University (EMU)-Doğu Akdeniz Üniversitesi (DAÜ)).

3. Boshoff D. Utilising sustainable tourism indicators to determine the environmental performance of Sun City Resort(Doctoral dissertation).

4. Świgost A. The transformation of the natural environment of the Polish and Ukrainian Bieszczady mountains due to tourism and other forms of human pressure. Current Issues of Tourism Research. 2017 Jan 26;5(2):27-35.

5. Shahgerdi, Amin, et al. "The Tourism-Environment Nexus; Challenges and Opportunities." Journal of Sustainable Development Studies 9.1 (2016).

5. Maršálek, Milan, Karel Houdek, and Emilie Pecharová. "The validation of the results of monitoring of tourist traffic on the example of selected hiking trails in the National Park Krkonose (Czechia)." Public recreation and landscape protection-with man hand in hand... (2013).

6. Sriarkarin, Supasit, and Chun-Hung Lee. "Integrating multiple attributes for sustainable development in a national park." Tourism Management Perspectives 28 (2018): 113-125.

7. Đorđević, Nataša, and Marija Kostić. "FACTORS THAT AFFECT THE TOURISTS PERCEPTION ABOUT THE DESTINATION ECOLOGICAL SUSTAINABILITY." INSTITUTE OF AGRICULTURAL ECONOMICS BELGRADE: 572.

8. Shujahi, Ayesha, and Anwar Hussain. "Economic and Environmental Costs of Tourism: Evidence from District Abbottabad."

9. Soni, Gagan, and Sarah Hussain. "A Study on the Impact of Tourism on the Himalayas." ECommerce for future \& Trends3.1 (2016): 27-35. 
10. Marshall, Greg W., et al. "Revolution in sales: The impact of social media and related technology on the selling environment." Journal of Personal Selling \& Sales Management 32.3 (2012): 349-363.

\section{ECOTOURISM AS AN INSTRUMENT TO CONSERVE BIODIVERSITY Andreas Hohl} (Ecotourist Travel Guide, Germany) Handbook of Tourism Economics. May 2013, 813-843

12. Douglas G. Pearce (1985) Tourism and environmental research: a review, International Journal of Environmental Studies, 25:4, 247-255, DOI: 10.1080/00207238508710233

13. Mallick, Rwitabrata and Shri Prakash Bajpai. "Impact of Social Media on Environmental Awareness." Environmental Awareness and the Role of Social Media. IGI Global, 2019. 140-149. Web. 2 Apr. 2019. doi:10.4018/978-1-5225-5291-8.ch007

14. Nwagbara, Dr Uzoechi. (2013). The Effects of Social Media on Environmental Sustainability Activities of Oil and Gas Multinationals in Nigeria. Thunderbird International Business Review. 55. 10.1002/tie.21584.

15. Hamid, Suraya \& Ijab, Mohamad \& Sulaiman, Hidayah \& Md. Anwar, Rina \& Norman, Azah. (2017). Social media for environmental sustainability awareness in higher education. International Journal of Sustainability in Higher Education. 18. 474-491. 10.1108/IJSHE-01-2015-0010.

16. Rahim, Mariwan \& Jalaladeen, Jwan. (2016). The Role of Social Media on Environmental Awareness of Undergraduate Students in University of Sulaimani in Iraq. Journal of Arts, Literature, Humanities and Social Sciences - JALHSS. 10. 218-231.

17. Tlebere, T \& Scholtz, Brenda \& Calitz, André. (2015). Using Social Media to Improve Environmental Awareness in Higher Education Institutions.

18. Scholtz, Brenda \& Burger, Clayton \& Zita, Masive. (2016). A Social Media Environmental Awareness Campaign to Promote Sustainable Practices in Educational Environments. 10.1007/978-3319-23455-7_19.

19. Wu, Yinglin \& Xie, Ling \& Huang, S.-L \& Li, Ping \& Yuan, Zengwei \& Liu, Wenhua. (2018). Using social media to strengthen public awareness of wildlife conservation. Ocean and Coastal Management. 153. 76-83. 10.1016/j.ocecoaman.2017.12.010.

20. Kwok, Linchi \& Xie, Karen \& Richards, Tori. (2017). Thematic framework of online review research: A systematic analysis of contemporary literature on seven major hospitality and tourism journals. International Journal of Contemporary Hospitality Management. 29. 10.1108/IJCHM-11-20150664.

21. Nicole L. Boivin, Melinda A. Zeder, Dorian Q. Fuller, Alison Crowther, Greger Larson, Jon M. Erlandson, Tim Denham, Michael D. Petraglia. Proceedings of the National Academy of Sciences Jun 2016, 113 (23) 6388-6396; DOI: 10.1073/pnas.1525200113 